\section{THU0475 INCIDENCE AND DETERMINANTS OF VERTEBRAL AND PERIPHERAL FRACTURES IN PATIENTS WITH SYSTEMIC LUPUS ERYTHEMATOSUS: A PROSPECTIVE LONGITUDINAL COHORT STUDY}

F. El Hadiyen ${ }^{1}$, M. Tsang-A-Sjoe ${ }^{1}$, M. ter Wee ${ }^{1,2}$, A. Voskuyl ${ }^{1}$, W. Lems ${ }^{1}$, I. Bultink'. ${ }^{1}$ Department of Rheumatology; ${ }^{2}$ Department of Epidemiology and Biostatistics, VU University Medical Center, Amsterdam, Netherlands

Background: Systemic lupus erythematosus (SLE) is associated with an increased risk of fractures ${ }^{1}$. However, data on the incidence of vertebral and peripheral fractures are limited. In particular, data on (morphometric) vertebral fracture incidence and determinants of such fractures are scarce and show conflicting results.

Objectives: To assess the incidence of fractures in a population of patients with SLE, and to identify determinants that predict incident vertebral and peripheral fractures.

Methods: A prospective longitudinal cohort study in 145 patients with SLE was performed. Serial bone mineral density (BMD) measurements using dual x-ray absorptiometry, and radiographs of the thoracic and lumbar spine were performed at inclusion and after a median of 5 years (IQR 3-5) follow-up. Demographic and clinical data were also collected. Vertebral fractures were scored according to the semi-quantitative method by Genant et al. Reported peripheral fractures were confirmed by $x$-rays. Analyses were performed with logistic regression (forward selection procedure, $\mathrm{p}$-value of 0.05 as cut-off level). The outcome measures were incident fracture in general (yes/no), vertebral fracture (yes/no), and peripheral fracture (yes/no)

Results: Of the 145 included patients, $131(90 \%)$ were females and $100(69 \%)$ Caucasian. The mean age was 41 years (SD 12) at baseline, and median followup was 7.2 years (IQR 6-12). A total of 42 incident fractures (vertebral and peripheral) occurred during 998 patient years. The incidence rate of vertebral and peripheral fractures was 2.0 per 100 patient years $(95 \% \mathrm{Cl} 1.30-3.13)$, and 2.20 per 100 patient years $(95 \% \mathrm{Cl} 1.45-3.35)$, respectively.

Any fracture (both vertebral and peripheral) was predicted by postmenopausal status and Caucasian ethnicity. Vertebral fractures were predicted by age, in which the older the SLE patient, the higher the odds of getting vertebral fractures. Peripheral fractures were predicted by history of stroke, postmenopausal status and moderate alcohol use (1-12 units per week). Use of higher dosages of alcohol ( $>13$ units per week) did not reduce peripheral fracture occurrence. Table 1 shows the final prediction models.

Conclusions: The results of our study suggest a twofold increased risk of both vertebral and peripheral fractures in SLE patients compared to the general population $^{1,2}$. Age, Caucasian ethnicity and postmenopausal status are important risk factors for incident fractures in SLE. In addition, special attention should be paid to SLE patients with a history of stroke since this subgroup of patients is at high risk of peripheral fractures.

\section{REFERENCES:}

[1] Bultink IEM, et al. Osteoporos Int 2014;25:1275-83

[2] Ballane G, et al. Osteoporos Int 2017;28:1531-42.

Disclosure of Interest: F. El Hadiyen: None declared, M. Tsang-A-Sjoe: None declared, M. ter Wee: None declared, A. Voskuyl: None declared, W. Lems: None declared, I. Bultink Speakers bureau: Lilly Netherlands, MSD, Amgen BV, UCB Pharma BV, Sanofi Genzyme BV

DOI: 10.1136/annrheumdis-2018-eular.5938

\section{THU0476 \\ SPONTANEOUS VERTEBRAL FRACTURESAFTER DENOSUMAB DISCONTINUATION: A REPORT OF 6 CASES}

H. Florez, J. Ramírez, A. Monegal, N. Guañabens, P. Peris. Department of Rheumatology, Hospital Clínic, Barcelona, Spain

Background: Denosumab (Dmab) is an antiresorptive treatment with demonstrated efficacy in osteoporosis. However, discontinuation of Dmab has been associated with rapid bone loss, and recently, the development of vertebral fractures (VF) in some patients. It is essential to identify the risk factors for these adverse events and follow its evolution.

Objectives: To analyse the clinical characteristics, parameters of bone metabolism and evolution of patients developing VF after Dmab discontinuation.

Methods: Six women with spontaneous VF after Dmab discontinuation were included (median age 66 years ${ }^{56-75}$ ). The clinical history, cause of osteoporosis, treatments received, fractures, Dmab treatment duration and discontinuation period were reviewed. Additionally, the clinical and densitometric evolution, and bone mineral parameters were also analysed after Dmab discontinuation.

Results: All the patients had postmenopausal osteoporosis, and one was receiving glucocorticoid treatment; $3 / 6$ patients had previous fractures ( $2 \mathrm{VF}$ and $1 \mathrm{cal}-$ caneus); $4 / 6$ had previously received antiosteoporotic treatment (hormone replacement therapy, risedronate, alendronate, zoledronate [once or consecutively)] during 1-23 years. All had received Dmab for 24-53 months (median 37). The reasons for treatment discontinuation were: dental indication (1 patient), BMD improvement (T-score -1.2) (1 patient), poor adherence, ${ }^{1}$ prescription problems and/or delay in administration. ${ }^{3}$ The median bone mineral density T-scores prior to VF were $-2.6(-1.2 /-4)$ at the lumbar spine and $-3.0(-0.6 /-3.7)$ at the femoral neck. The mean time between the last Dmab dose and VF was 9.5 months, ${ }^{8-20}$ with a median of $5 \mathrm{VFs} /$ patient. $^{2-8}$ No patient showed $25-\mathrm{OH}$ vitamin $\mathrm{D}<20 \mathrm{ng} / \mathrm{ml}$. After Dmab discontinuation, bone turnover markers increased (median increase $+364 \%$ in PINP and $+287 \%$ in NTx); one patient presented hypercalcae$\mathrm{mia}$ (Ca $11.3 \mathrm{mg} / \mathrm{dL}$ ); and BMD decreased $1 \%-21 \%$ in the lumbar spine and $2 \%-$ $6 \%$ in total hip at 8-19 months. After VF, 3 patients restarted Dmab, 1 received zoledronate and 2 alendronate. No new fractures occurred during follow-up.

Conclusions: Discontinuation of Dmab is associated with an increase in bone turnover markers and bone loss which can be associated with the development of spontaneous VF. Previous bisphosphonate therapy does not seem to decrease this risk. Further studies are needed to assess the optimal antiresorptive treatment and its duration after Dmab discontinuation.

Disclosure of Interest: None declared

DOI: 10.1136/annrheumdis-2018-eular.4896

\section{THU0477 FACTORS ASSOCIATED WITH THE INITIATION OF TREATMENT AFTER FRAGILITY FRACTURE IN A FRACTURE LIAISON SERVICE}

A. Saavedra ${ }^{1}$, A. Naranjo ${ }^{1}$, S. Ojeda ${ }^{1}$, R. Lopez ${ }^{1}$, A. Molina ${ }^{1}$, C. Alonso ${ }^{2}$, I. Bernardos ${ }^{1}$, C. Rodriguez-Lozano ${ }^{1} .{ }^{1}$ Rheumatology; ${ }^{2}$ Radiology, Hospital Univ. Gran Canaria Dr. Negrin, Las Palmas de Gran Canaria, Spain

Background: Adherence to treatment in osteoporosis (OP) is not adequate, so that in the first year the percentage of suspensions is between $30 \%$ and $50 \%$, up to an adherence of $20 \%$ at 3 years. In 2012, we started in Gran Canaria a Fracture Liaison Service (FLS).

Abstract THU0475 - Table 1. Multivariate logistic regression analyses of independent explanatory variables that predict incident fracture, showing OR and $95 \% \mathrm{Cl}$

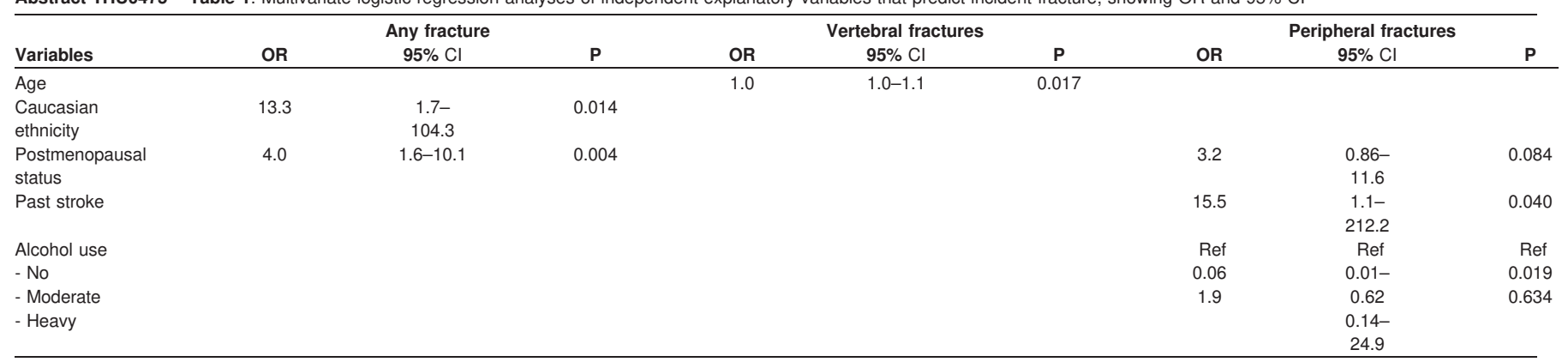


Objectives: To describe the factors associated to an effective initiation of treatment after the baseline visit to our FLS.

Methods: Prospective observational study that consists of: 1) training of primary care physicians (GP), 2) capture of patients; 3) baseline visit: questionnaire including FRAX; 4) Bone densitometry; 5) patient education by a Nurse with special attention to adherence; 6 ) referral to GP with a report with management recommendations; those with multiple fractures or who require parenteral therapy were referred to rheumatology; and 7) follow-up by telephone survey to check whether the treatment was taking and confirmation of the prescription in the electronic records (both of which are necessary to consider an effective start of treatment). The variables included were: sex, age, type of fracture, use of previous bisphosphonate, type of prescribed treatment, prescribing physician and causes of non-adherence.

Results: Up to December 2017, the adherence of 887 patients with fragility fractures to whom a bisphosphonate or equivalent was prescribed, was recorded. Treatment was initiated in the following 3 months by $74 \%(n=656)$ of patients. The following variables were associated with the initiation of treatment: female sex, previous treatment with antiresorptives, prescription of denosumab vs bisphosphonate and treatment precribed by a rheumatologist vs GP (table 1). The causes of not initiating or withdrawing the treatment at 3 months are shown in table 2 . In the regression analysis, we found a significant association with the effective initiation of treatment with a pevious treatment with bisphosphonate $(p<0.01)$, initiation of treatment by the rheumatologist $(p=0.01)$ and prescription of denosumab vs bisphosphonate $(p<0.01)$

Abstract THU0477 - Table 1. Factors associated to start of treatment at 3 months ${ }^{*} \mathrm{p}<0,01$

\begin{tabular}{lcc}
\hline & $\begin{array}{c}\text { Patients that initiate } \\
\text { treatment }(\mathrm{n}=656)\end{array}$ & $\begin{array}{c}\text { Patients who did not initiate or } \\
\text { stop treatment }(\mathrm{n}=231)\end{array}$ \\
\hline Female/Male, $\mathrm{n}(\%)$ & $577(76) / 79(63)^{*}$ & $185(24) / 46^{37}$ \\
Age, mean (SD) & $76(9)$ & $76(9)$ \\
Type o fracture, $\mathrm{n}(\%)$ Wrist/Hip & $191(29) / 213^{32}$ & $71(31) / 68^{29}$ \\
$\begin{array}{l}\text { Previous treatment with } \\
\text { Bisphosphonate, } \mathrm{n}(\%) \text { Yes/No }\end{array}$ & $178(91) / 478(69)^{\star}$ & $18(9) / 213^{31}$ \\
$\begin{array}{l}\text { Prescription of Bisphosphonate/ } \\
\text { denosumab } \mathrm{n}(\%)\end{array}$ & $446(70,5) / 203(80)^{\star}$ & $186(29,5) /$ \\
$\begin{array}{l}\text { Prescription by Primary Care/ } \\
\text { Rheumatology, } \mathrm{n}(\%)\end{array}$ & $412(69,5) / 230(82)^{*}$ & $180(30,5) / 51^{18}$ \\
\hline
\end{tabular}

Abstract THU0477 - Table 2. Causes of no start or stop treatment, N (\%)

\begin{tabular}{lc}
\hline No prescription/suspension by GP & $115(50)$ \\
\hline Patient related causes & $93(40)$ \\
Patient does not want the treatment & $39(17)$ \\
Polipharmacy & $20(9)$ \\
Dont know/Did not visit the GP & $20(9)$ \\
Drug intolerance & $14(6)$ \\
Other causes & $23(10)$ \\
\hline
\end{tabular}

Conclusions: $74 \%$ of patients seen in the FLS start treatment within 3 months of the baseline visit. The factors associated with the initiation of therapy were prior antiresorptive treatment, denosumab prescription and initial prescription by the rheumatologist. The reason of non adherence in half of the cases is the GP's refusal to initiate or continue the FLS recommendation.

Disclosure of Interest: None declared

DOI: 10.1136/annrheumdis-2018-eular.4659

\section{THU0478 BEFORE AND AFTER MENOPAUSE, OSTEOPOROSIS RISK FACTORS ARE DIFFERENT IN WOMEN WITH RHEUMATOID ARTHRITIS}

J.-F. Chen, T.-T. Cheng, S.-F. Yu, Y.-C. Chen, C.-Y. Hsu, H.-M. Lai, F.-M. Su, B. Y.-J. Su, W.-C. Chiu. Division of Rheumatology, Allergy, and Immunology, Department of Internal Medicine, Kaohsiung Chang Gung Memorial Hospital and Chang Gung University College of Medicine, Kaohsiung, Taiwan, Province of China

Background: Rheumatoid arthritis (RA) is an autoimmune disease characterised by systemic inflammation, involving not only the juxta-articular bone erosion, but generalised bone loss[. ${ }^{1}$ Sex hormone activates RA disease activity and induced bone resorption, but hormone replacement therapy increases bone mass and density. The ambiguous role of sex hormone on bone remodelling is confusing in RA patients. Under the impact of sex hormone, risk factors for osteoporosis might be different at pre- and post-menopausal stage.

Objectives: To investigate the different clinical risk factors of osteoporosis in preand post-menopausal women with RA.

Methods: A cross-sectional study was performed during 2014 to 2017 , enrolling female participants fulfilled 2010 RA criteria[. ${ }^{2}$ We recorded demographic data, risk factors for osteoporosis and blood test. Osteoporosis is defined if one of hip, distal forearm, and lumbar spine bone mineral density less than -2.5 by T-score for post-menopausal women, or less than -2.0 by Z-sore for pre-menopausal women. Data was analysed by Student's $t$ test and Chi-square test for continuous and categorical valuables, respectively. Multivariate logistic regression was applied to detect association of osteoporosis and selected variables.

Results: A total of 451 participants were enrolled in the study, including 89 preand 362 post-menopausal women. The prevalence of osteoporosis is $14.6 \%$ and $36.7 \%$ for pre- and post-menopausal women with RA, respectively. At pre-menopause, low body weight is the only significant risk factors for osteoporosis, while old age, low body height, low body weight, positive anti-cyclic citrullinated peptide antibody (anti-CCP), previous fracture history, elevated white blood cell and platelet count, and lower calcium level are potential risk factors for post-menopausa women developing osteoporosis (table 1). Multivariate stepwise logistic regres sion analysis (table 2) showed body weight remains the leading risk factors in premenopausal women (Odds ratio[OR] $=0.84,95 \%$ confidence interval $[\mathrm{CI}$ $=0.76 \sim 0.94$, P-value $=0.002$ ), while body weight and previous fracture history are significant risk factors in post-menopausal women(body weight OR=0.91, 95\% $\mathrm{Cl}=0.88 \sim 0.94$, $\mathrm{P}$-value $<0.001$. previous fracture $\mathrm{OR}=2.03,95 \% \mathrm{Cl} 1.13 \sim 3.64, \mathrm{P}$ value 0.02 )

Conclusions: Risk factors of osteoporosis are different in pre- and post-menopausal women with RA. For pre-menopausal women, Low body weight is a leading risk factor, while low body weight and previous fracture history are important for post-menopausal women. Without protection of sex hormone, there are Potential roles of anti-CCP and white blood cell participating in osteoporosis pathogenesis and need more survey for confirmation.

\section{REFERENCES}

[1] Lems WF, Dijkmans BA: Should we look for osteoporosis in patients with rheumatoid arthritis? Ann Rheum Dis 1998, 57(6):325-327.

[2] Aletaha D, Neogi T, Silman AJ, Funovits J, Felson DT, Bingham CO, 3rd, Birnbaum NS, Burmester GR, Bykerk VP, Cohen MD, et al. 2010 rheumatoid arthritis classification criteria: an American College of Rheumatology/European League Against Rheumatism collaborative initiative. Ann Rheum Dis 2010,69(9):1580-1588.

Acknowledgements: Special thanks to Dr. Tien-Tsai, Cheng for his effort to establish the RA-GIOP database.

Disclosure of Interest: None declared

DOI: 10.1136/annrheumdis-2018-eular.1488

\section{THU0479 THE ANTIOSTEOPOROTIC TREATMENT IS SCARCE AMONG PATIENTS WITH VERTEBRAL FRACTURE REFLECTED IN THE RADIOLOGICAL REPORT: DATA FROM A FRACTURE UNIT-FLS}

A. Pons-Bas ${ }^{1}$, J. Rosas $^{1,1}$, M. Hernández ${ }^{2}$, C. Cano ${ }^{1}$, E. Ivars ${ }^{1}$, M. Lorente ${ }^{1}$, J. Hernández ${ }^{2}$, G. Santos-Soler ${ }^{1}$, A. García ${ }^{2}$, E. Salas ${ }^{1}$, H. Arcos ${ }^{2}$, J.M. SenabreGallego $^{1}$, J. Alvarado ${ }^{2}$, J. Jiménez ${ }^{2}$, C. López ${ }^{2}$, M. López ${ }^{2}$, A. Molinos ${ }^{2}$, B. Statti ${ }^{2}$, V. Miñanos ${ }^{2}$, J. Monteagudo ${ }^{2}$, X. Barber ${ }^{3}$, on behalf of AIRE-MB Group.

${ }^{1}$ Rheumatology Department, ${ }^{2}$ Radiology Department, Hospital Marina Baixa,

Villajoyosa (Alicante); ${ }^{3} \mathrm{COI}$, Miguel Hernández University, Elche, Spain

Background: A relevant number of patients with vertebral fracture (VF) do not receive specific treatment for osteoporosis and remain as invisible fractures. The objective of the Fracture Units-FLS is to detect patients with fracture, to perform an adequate diagnostic evaluation, initiate treatment and try to prevent new fractures.

Objectives: To know the characteristics of the patients and attitude of the referring service, in which the radiological report identifies the presence of VF.

Methods: Observational study carried out from January 1 to June 30, 2017, of consecutive patients in which the radiological report after performing simple radiology or CT, reflects the presence of dorsal, lumbar or both VF. The attitude of the service requesting the radiological test was reviewed 3 months after the radiological report.

The following variables were collected: general data of the patients (age, gender), the service requesting the imaging test (specialty, request from hospitalisation or ambulant, diagnosis and/or previous treatment for osteoporosis, attitude towards the FV) and the radiological test (type of test and location of the VF).

Results: 91 patients were included, of which $62 \%$ were women, with a mean age of $72 \pm 11.56$ years. In $46 \%$ of the patients, the image test was requested by one of the Internal Medicine Services (gastroenterology: 31\%, oncology-haematology: $17 \%$, rheumatology: $14 \%$, neumology: $12 \%$, cardiology: $10 \%), 36 \%$ by Primary Care Physicians, $15 \%$ from the Emergency Department of the Hospital and the remaining $2 \%$ from a Surgical Service.

In $77 \%$, the radiological test was given to ambulatory patients. In $56 \%$, the imaging test was simple radiology (chest $\mathrm{X}$-ray: $56 \%$, dorsal-lumbar spine: $41 \%$ and the 